\title{
Long-Term Management of the Kidney Transplant Recipient
}

\author{
Heidi M. Schaefer \\ Division of Nephrology, Department of Medicine, Vanderbilt University School of Medicine, Nashville, Tenn., USA
}

\section{Key Words}

Kidney transplantation • Hypertension • Anemia •

Dyslipidemia • Diabetes - Allograft function • Infection •

Malignancy

\begin{abstract}
Due to the successes of kidney transplantation, patients with allografts are enjoying long-term survival. In addition to care of the allograft with lifelong administration of immunosuppressive medications, common medical conditions must be recognized and managed appropriately. With constraints on the transplant centers and patient considerations of finance and geography, it is recognized that community providers will play an ever increasing role in the care of the kidney transplant recipient. Guidelines for understanding and managing some of the more important common general medical problems, including care as it relates to cardiovascular disease, chronic kidney disease, transplant-related issues, and general health maintenance, are reviewed in this article.
\end{abstract}

Copyright $\odot 2012$ S. Karger AG, Base

\section{Introduction}

Kidney transplantation remains the treatment of choice for patients with end-stage renal disease. With significant advances in short-term outcomes primarily driven by advances in immunosuppression with low acute re- jection rates, a large percentage of patients have longterm survival with functioning allografts. As of 2007, over 140,000 patients in the United States had functioning allografts [1]. These patients present with a particular and complex set of medical issues that require intensive management to allow for longevity of both the patient and the allograft. Due to constraints of the transplant center and a limited number of transplant nephrologists, it is imperative that the community nephrologist and primary care provider have an understanding of the complex and interacting medical issues these patients face. Common aspects of medical care of the transplant recipient will be discussed here.

\section{Cardiovascular Disease}

Although successful kidney transplantation confers a notable increase in life expectancy over dialysis therapy for patients with end-stage renal disease, the survival of kidney transplant recipients is significantly shortened by atherosclerotic cardiovascular disease (CVD) $[2,3]$. The annual risk of CVD death is 3.5-5\% in kidney transplant recipients, which is 50 -fold higher than in the general population [4] and is the primary etiology of death with a functioning graft. In addition to the CVD burden carried over from end-stage renal disease, transplant recipients encounter several factors in the post-transplant period that further accentuate the prevalence and severi-

\section{KARGER \\ Fax +4161306 1234 E-Mail karger@karger.ch} www.karger.com
(C) 2012 S. Karger AG, Basel

0253-5068/12/0333-0205\$38.00/0

Accessible online at:

www.karger.com/bpu
Heidi M. Schaefer, MD

1161 21st Avenue South, S3223 Medical Center North

Vanderbilt University Medical Center

Nashville, TN 37232-2372 (USA)

Tel. +1 615322 6976, E-Mail heidi.schaefer@vanderbilt.edu 
Table 1. Cardiovascular risk factor management in the transplant recipient

\begin{tabular}{|c|c|c|c|c|}
\hline Risk factor & Guideline & Goal of treatment & Treatment recommendations & Comments \\
\hline Hypertension & K/DOQI & $<130 / 80 \mathrm{~mm} \mathrm{Hg}$ & $\begin{array}{l}\text { lifestyle modification; } \\
\text { calcium channel blocker; } \\
\text { ACE-I/ARB if proteinuria present; } \\
\beta \text {-blocker if known CVD }\end{array}$ & $\begin{array}{l}\text { avoid diltiazem/verapamil due to } \\
\text { interactions with calcineurin inhibitors }\end{array}$ \\
\hline Dyslipidemia & NCEP III & $\begin{array}{l}\text { total cholesterol }<200 \\
\mathrm{LDL}<100 \\
\text { triglycerides }<150\end{array}$ & $\begin{array}{l}\text { lifestyle modification; } \\
\text { statins; fibrates; ezetimibe }\end{array}$ & $\begin{array}{l}\text { avoid bile acid sequestrants; monitor } \\
\text { for hepatitis, myositis, and rhabdomy- } \\
\text { olysis when using statin/fibrate drugs }\end{array}$ \\
\hline NODAT & KDIGO & target $\mathrm{HbA}_{1 \mathrm{C}} 7.0-7.5 \%$ & $\begin{array}{l}\text { lifestyle modification; } \\
\text { oral agents; insulin }\end{array}$ & $\begin{array}{l}\text { increased risk of lactic acidosis with use } \\
\text { of metformin }\end{array}$ \\
\hline Anemia & K/DOQI & target Hgb $11-12$ g/dl & $\begin{array}{l}\text { iron (intravenous and oral); } \\
\text { recombinant erythropoietin }\end{array}$ & $\begin{array}{l}\text { avoid liberal use of recombinant eryth- } \\
\text { ropoietin due to possible increased risk } \\
\text { of thrombotic and vascular events }\end{array}$ \\
\hline Obesity & KDIGO & $\mathrm{BMI}<35-40$ & $\begin{array}{l}\text { lifestyle modification; referral } \\
\text { to dietician; bariatric surgery }\end{array}$ & \\
\hline Tobacco abuse & KDIGO & smoking cessation & $\begin{array}{l}\text { behavioral counseling; } \\
\text { pharmacologic therapy }\end{array}$ & \\
\hline
\end{tabular}

K/DOQI = Kidney Disease Outcome Quality Initiative; NCEP III = National Cholesterol Education Program Report of the Expert Panel; NODAT = new-onset diabetes after transplantation; KDIGO = Kidney Disease Improving Global Outcomes; ACE-I = angiotensin-converting enzyme inhibitor; $\mathrm{ARB}=$ angiotensin receptor blocker; $\mathrm{HbA} 1 \mathrm{C}=$ hemoglobin $\mathrm{AlC}$; $\mathrm{Hgb}=\mathrm{hemoglobin}$; $\mathrm{CVD}=$ cardiovascular disease.

ty of several CVD risk factors. It is well recognized that immunosuppressive agents have associated effects on hypertension, dyslipidemia, and diabetes [3]. Aggressive management of these factors must be carried out by the treating nephrologist (table 1).

\section{Hypertension}

Hypertension is the most prevalent CVD risk factor in kidney transplant recipients, affecting up to $80 \%$ of patients [5]. In addition to essential hypertension, primary kidney disease, quality of donor organ, delayed graft function, acute rejection, calcineurin inhibitor (CNI) therapy, glucocorticoids, transplant renal artery stenosis, and chronic allograft nephropathy all contribute to the pathogenesis of post-transplant hypertension [6]. Based on a variety of published guidelines, the recommended treatment goal for hypertension in transplant recipients is $<130 / 80 \mathrm{~mm} \mathrm{Hg}$. In addition to lifestyle modifications including weight loss, dietary sodium restriction, and physical exercise, the majority of transplant recipients will require medical therapy to achieve the target blood pressure.

Most classes of antihypertensive agents have been used and are effective in treating kidney transplant re- cipients, but it is important to recognize that the pharmacologic management of hypertension in this population presents several unique issues related to potential drug interactions and side effects. Calcium channel blockers have been used as first-line agents due to their vasodilatory properties that may counteract the vasoconstrictive effects of CNI. It should be noted, however, that verapamil and diltiazem significantly interact and raise CNI levels with potential for nephrotoxicity, and should be avoided if possible. In patients who have known CVD, $\beta$-blockers are recommended as first-line agents. If the transplant recipient has significant proteinuria and/ or diabetes, angiotensin-converting enzyme inhibitors (ACE-I) or angiotensin receptor blockers (ARB) should be instituted due to their potential renoprotective effects, with close attention given to serum potassium levels.

\section{Dyslipidemia}

Post-transplant hyperlipidemia occurs in $60-80 \%$ of transplant recipients [7]. The evaluation and treatment of hyperlipidemia should follow National Cholesterol Education Program III clinical practice guidelines with target total cholesterol, low-density lipoprotein (LDL), and triglyceride values of $<200,100$, and $150 \mathrm{mg} / \mathrm{dl}$, respectively 
[8]. Statin drugs have been used safely for those patients who are unable to meet the recommended target levels with dietary modification and exercise alone. In one of the few randomized controlled trials in transplantation, the Assessment of Lescol in Renal Transplant (ALERT) trial demonstrated a significant reduction in LDL cholesterol, incidence of myocardial infarction, and cardiac death in patients randomized to fluvastatin [9]. For patients with significant hypertriglyceridemia, fibric acid derivatives such as gemfibrozil are recommended [10]. It should be recognized that both statins and fibrate drugs can interact with CNI and increase the risk of hepatitis, myositis, and rhabdomyolysis with close monitoring of patients recommended after institution of these agents. Ezetimibe in small studies has been shown to be well tolerated and effective in lowering LDL cholesterol when used alone and in combination with statin therapy [11].

\section{Diabetes}

New-onset diabetes after transplantation, which occurs in up to $25 \%$ of recipients, has been shown to both be a major risk factor for CVD after transplantation and have a deleterious effect on overall patient and graft survival [12]. Identified risk factors for the development of new-onset diabetes after transplantation include: African-American race, hepatitis $\mathrm{C}$, immunosuppressive medications, (tracrolimus, sirolimus, steroids), obesity, and hypertension [12].

All patients should be screened periodically for newonset diabetes after transplantation according to American Diabetes Association [13] criteria, including fasting plasma glucose levels $\geq 126 \mathrm{mg} / \mathrm{dl}$ or 2 -hour plasma glucose levels $\geq 200 \mathrm{mg} / \mathrm{dl}$. As with hyperlipidemia, dietary modification and exercise should be encouraged. In addition, modification of the immunosuppressive regimen should be considered with rapid tapering of corticosteroids and reduction in exposure to tacrolimus and sirolimus [14].

Chronic hyperglycemia management should follow the guidelines outlined by the American Diabetes Association for the treatment of individuals with type 2 diabetes [13]. The physician should set blood glucose targets for each individual patient and adjust therapy according to a 'treat to target' approach. If unable to reach the target with the above methods, oral glucose-lowering monotherapy or combination therapy and/or insulin is recommended. There are no specific recommendations regarding which oral agent to use, but caution should be taken if prescribing metformin due to the possibility of lifethreatening lactic acidosis, particularly in patients with renal failure, sepsis, and cardiovascular compromise. Referral to a diabetologist may be of benefit and patients should be counseled regarding regular opthalmological evaluation and foot care.

\section{Chronic Kidney Disease Care}

\section{Anemia}

Anemia is a common post-transplant complication and is estimated to occur in $30-40 \%$ of patients [15]. The American Society of Transplantation defines anemia as hemoglobin $<13 \mathrm{mg} / \mathrm{dl}$ for men and $<12 \mathrm{mg} / \mathrm{dl}$ for women [16]. At the time of kidney transplantation, most patients have anemia secondary to inadequate erythropoietin production and iron deficiency. Immediately after transplant, surgical blood loss, frequent phlebotomy, and allograft dysfunction may lead to continued anemia. In patients with well-functioning grafts, anemia usually resolves 3-6 months after transplantation [17]. There are a multitude of additional factors that may lead to anemia in the late post-transplant period ( $\geq 6$ months) including immunosuppressive agents (MMF, azathioprine, sirolimus) viral infections (parvovirus, EBV, CMV), and acute or chronic allograft dysfunction. Transplant providers should screen all kidney transplant patients routinely for anemia. In patients with anemia, follow-up testing should include iron studies, red blood cell indices, reticulocyte count, and occult blood for stool. If hemolytic anemia is suspected, bilirubin, haptoglobin, and lactate dehydrogenase should be measured. Although anemia has been shown to be an independent risk factor for post-transplant left ventricular hypertrophy and cardiovascular events [18], there is currently insufficient evidence to show that aggressive anemia management improves overall outcomes. It is recommended that the K/DOQI guidelines for the management of anemia in chronic kidney disease be followed in the transplant population [19], but until prospective randomized trials are carried out determining optimal hemoglobin targets in kidney transplant recipients, liberal use of recombinant erythropoietin should be avoided.

\section{Bone Metabolism}

Fracture rates between 6 and $45 \%$ have been reported after kidney transplantation [20]. A unique characteristic is that most of the fractures occur primarily in the appendicular skeleton, particularly the feet. Patients with a history of diabetes are at particular risk for peripheral fractures [21]. Many factors contribute to post-transplant 
bone disease, including pre-existing renal osteodystrophy, corticosteroid therapy, hormone deficiencies, persistent hyperparathyroidism, and hyperphosphaturia. Recipients of kidney transplants rapidly lose bone, with dual $\mathrm{X}$-ray absorptiometry scans showing a significant decrease in bone mineral density as early as 3-6 months after transplantation [22]. It is recommended that dual $\mathrm{X}$-ray absorptiometry scans be obtained at regular intervals after transplant. In addition, laboratory evaluation should include measurement of calcium, phosphorus, intact parathyroid hormone, and 25-hydroxyvitamin D levels.

The prevention and management of bone disease after transplant requires a multifactorial approach. Patients who are deemed to be at high risk for fractures should be identified pretransplant and the use of a steroid avoidance protocol should be considered. High-risk patients are those who are older, diabetic, and have a previous history of fracture, as well as those with extended dialysis duration before transplantation [20]. Other strategies to prevent early bone loss have been the use of vitamin $\mathrm{D}$ analogues and bisphosphonates. Although both therapies have been shown to prevent early bone loss in kidney transplant recipients, there are no controlled studies that demonstrate fracture prevention [23]. In addition, it is important to recognize that use of bisphosphonates has been associated with adynamic bone disease [24] and should be used with caution in kidney transplant recipients. Patients should have adequate calcium intake $(1,200$ $\mathrm{mg} /$ day) and 25-hydroxyvitamin D repleted to levels above $30 \mathrm{ng} / \mathrm{ml}$. In addition to pharmacologic therapies, nonpharmacologic measures should be employed to prevent early bone loss. These include regular physical exercise, weight resistance training, and improving balance and mobility.

\section{Transplant-Related Care}

\section{Allograft Dysfunction}

It is imperative that allograft function be assessed at routine intervals after transplantation through the measurement of serum creatinine values and urinalyses as reduced kidney allograft function is associated with poor patient and graft outcomes [25]. In the late post-transplant period, patients may present with acute kidney injury or a slow decline over time in allograft function, termed chronic allograft dysfunction. Acute kidney injury is most commonly related to volume depletion, drugs (CNI, ACE-I/ARB, NSAIDs), and urinary tract infec- tions. Acute rejection is rare in this period, but should be suspected if the treatment of other causes does not return the creatinine back to the previous baseline, or if the patient admits to noncompliance with their immunosuppressive regimen. In these particular instances, allograft biopsy should be performed. Causes of chronic allograft dysfunction include chronic allograft nephropathy, CNI nephrotoxicity, chronic active antibody-mediated rejection, and recurrent or de novo glomerulonephritis.

Chronic allograft nephropathy is associated with significant morbidity and mortality, and is the main reason for returning to dialysis after transplantation [26]. It is defined as a condition of renal allograft dysfunction occurring at least 3 months after transplantation without evidence of active acute rejection, drug toxicity, or other diseases. It is characterized clinically by gradual deterioration of graft function, increasing proteinuria, and worsening hypertension. Treatment of chronic allograft nephropathy can be challenging, but should focus on prevention of early acute rejection and, in subsequent years, limitation of CNI exposure. In addition, several studies have suggested that ACE-I and ARB may have a beneficial effect in prolonging allograft survival in recipients with chronic allograft nephropathy and proteinuria $[27,28]$.

Along with chronic allograft nephropathy, CNI nephrotoxicity plays a significant role in progressive kidney dysfunction after transplantation with most allografts showing histopathologic signs of CNI toxicity by 10 years [29]. A variety of tactics have been employed to try to limit CNI toxicity through CNI avoidance, early withdrawal, or minimization. Several systematic reviews have shown higher creatinine clearance in patients withdrawn from CNI and treated with sirolimus-based therapy [30, 31].

Chronic antibody-mediated rejection is defined by the presence of donor-specific antibodies in the recipient serum and C4d deposition in the peritubular capillaries. These patients present with significant proteinuria as a result of transplant glomerulopathy, a specific glomerular lesion thought to be the result of immune injury. $\mathrm{Pa}-$ tients who are considered to at high risk immunologically at the time of transplant may benefit from DSA screening and subsequent adjustment of immunosuppression. Finally, glomerulonephritis, both recurrent and de novo, can occur at any time after transplantation and contribute to loss of the allograft. Focal and segmental glomerulosclerosis, membranoproliferative glomerulonephritis, and hemolytic uremic syndromes are the disorders known to be most aggressive when they recur. Recurrent and de novo glomerulonephritis is associated with a twofold increase in risk for graft loss [32] and 
should be considered in any patient presenting with proteinuria, hematuria, and a decline in allograft function. Biopsy with both electron microscopy and immunofluorescence staining should be performed.

\section{Infections}

Infections occurring in the transplant recipient are common with the risk of infection determined primarily by the intensity of the immunosuppression and epidemiologic exposures of the individual (donor-derived infections, recipient-derived infections, nosocomial infections, and community infections). The incidence and severity of early post-transplant infections has been dramatically reduced by the use of antimicrobial prophylaxis. Most transplant centers use trimethoprim-sulfamethoxazole for prophylaxis against Pneumocystis carinii pneumonia for at least 6 months after surgery. In addition to $P$. carinii pneumonia, the drug can prevent infections with common urinary, respiratory, and gastrointestinal pathogens. Dapsone, atovaquone, and pentamidine are alternative agents that may be used in the case of sulfa allergy [33]. Cytomegalovirus prophylaxis should also be instituted, with most centers using oral valganciclovir for at least 4 months after transplantation. Based on the results of the Improved Protection Against CMV in Transplant (IMPACT) trial, patients deemed highest risk (donor + / recipient -) should receive 6 months of therapy [34].

Due to a reduction in overall immunosuppression exposure, the risk of infection diminishes 6 months after transplantation, with the most common infections being community-acquired respiratory illnesses. In addition, urinary tract infections are quite common, and most would argue for the routine surveillance of urinary tract infections with urine cultures obtained at each posttransplant visit. In patients who receive increased immunosuppression due to acute rejection episodes, increased vigilance against opportunistic infections including P. carinii, Listeria monocytogenes, Nocardia asteroides, Cryptococcus neoformans, and Aspergillus should be undertaken. In addition to prophylactic therapy, all patients should be appropriately vaccinated to prevent infectious complications. Guidelines on vaccinations are available on the American Society of Transplantation website (www.a-s-t.org). It is important to remember that live vaccines should be avoided in transplant recipients. Recipients should receive a yearly influenza vaccination and pneumococcal vaccination every 5 years after initial vaccination. Patients travelling overseas should receive appropriate counseling and vaccinations as needed prior to their trip [35].

Medical Care after Kidney

Transplantation

\section{Malignancy}

It is important to recognize that transplant recipients are at increased risk for malignancy as compared to the general population, primarily related to the chronic use of immunosuppressive medications. Neoplasms that have a higher incidence after transplantation include nonmelanomatous skin cancers, Kaposi's sarcoma, nonHodgkin lymphoma, renal cell carcinoma, leukemia, hepatobiliary cancer, cervical cancer, and vulvovaginal cancers [36]. Noted risk factors for malignancy are age, smoking, immunosuppression, and chronic viral infections [37]. Kidney transplant recipients should undergo an annual skin exam and be counseled regarding sun protective measures. Age-appropriate cancer screening including prostate-specific antigen measurements, fecal occult blood testing, breast exam and mammography, Pap smear, and colonoscopy should be performed as indicated. Along with antitumor therapy, several studies have suggested that adjustment of the immunosuppressive regimen with a switch from CNI to sirolimus may be helpful in modifying the course of the malignancy [38].

\section{General Health Maintenance}

\section{Pregnancy}

As fertility can be restored to normal soon after a kidney transplant, it is important for physicians caring for recipients to be able to inform the patient about the potential risks of pregnancy. Current opinion is that pregnancy can be successful if carried out under optimal circumstances, including stable allograft function for at least 1 year after transplantation without rejection, good control of blood pressure, and appropriate adjustment of immunosuppression and other known teratogenic medications prior to conception [39]. In planning for pregnancy, one should discuss pregnancy outcomes and the risks for both the mother and fetus. During pregnancy, it is important to pay close attention to medical complications such as worsening of hypertension and development of preeclampsia, risk of infection (in particular of the urinary tract), and worsening anemia. Pregnant recipients should be managed in close conjunction with a high-risk obstetrician.

\section{Preventive Care}

Patients should be counseled on the need for lifestyle modification after transplantation. Many transplant patients gain excess weight due to increased caloric intake and lack of routine physical activity. Female, black, low- 
income patients with type 2 diabetes are at highest risk for obesity [40]. Obesity may exacerbate the cardiovascular risk profile (hypertension, hyperlipidemia, and diabetes) affecting long-term allograft and patient outcomes negatively [40]. It is important that patients receive appropriate counseling regarding healthy dietary practices, and they may benefit from consultation with a transplant dietician. Along with obesity, smoking tobacco has also been shown to exacerbate the cardiovascular risk profile. Kidney transplant recipients should be strongly discouraged from smoking as it has been shown to contribute significantly to allograft loss [41]. Both behavioral counseling and pharmacologic therapy should be recommended to the transplant recipient to aid in smoking cessation.

\section{Conclusion}

Kidney transplant recipients present with a unique and complex set of medical issues. As patients survive longer with functioning allografts, the responsibility for their care will become increasingly dependent on the community nephrologist and primary care physicians. It is crucial that these providers have the necessary skills and knowledge to provide appropriate care to these recipients, ensuring optimum health. Diligence and early intervention of transplant-related complications and cardiovascular risk factors should be undertaken with assistance from published guidelines and the transplant centers with the hope of improving long-term outcomes.

\section{References}

1 Wolfe RA, Roys EC, Merion RM: Trends in organ donation and transplantation in the United States, 1999-2008. Am J Transplant 2010;10:961-972.

2 Wolfe RA, Ashby VB, Milford EL, Ojo AO, Ettenger RE, Agodoa LY, et al: Comparison of mortality in all patients on dialysis, patients on dialysis awaiting transplantation, and recipients of a first cadaveric transplant. N Engl J Med 1999;341:1725-1730.

-3 Kasiske BL: Ischemic heart disease after renal transplantation. Kidney Int 2002;61: 356-369.

-4 Ojo AO: Cardiovascular complications after renal transplantation and their prevention. Transplantation 2006;82:603-611.

5 Campistol JM, Romero R, Paul J, GutierrezDalmau A: Epidemiology of arterial hypertension in renal transplant patients: changes over the last decade. Nephrol Dial Transplant 2004;19(suppl 3):iii62-iii66.

-6 Kasiske BL, Anjum S, Shah R, Skogen J, Kandaswamy C, Danielson B, et al: Hypertension after kidney transplantation. Am J Kidney Dis 2004;43:1071-1081.

7 Kobashigawa JA, Kasiske BL: Hyperlipidemia in solid organ transplantation. Transplantation 1997;63:331-338.

-8 Executive Summary of the Third Report of the National Cholesterol Education Program (NCEP) Expert Panel on Detection, Evaluation, and Treatment of High Blood Cholesterol in Adults (Adult Treatment Panel III). JAMA 2001;285:2486-2497.

-9 Jardine AG, Holdaas H, Fellstrom B, Cole E, Nyberg G, Gronhagen-Riska C, et al: Fluvastatin prevents cardiac death and myocardial infarction in renal transplant recipients: post-hoc subgroup analyses of the ALERT Study. Am J Transplant 2004;4:988-995.
10 Kasiske B, Cosio FG, Beto J, Bolton K, Chavers $\mathrm{BM}$, Grimm $\mathrm{R}$ Jr, et al: Clinical practice guidelines for managing dyslipidemias in kidney transplant patients: a report from the Managing Dyslipidemias in Chronic Kidney Disease Work Group of the National Kidney Foundation Kidney Disease Outcomes Quality Initiative. Am J Transplant 2004;4(suppl 7):13-53.

$\checkmark 11$ Puthenparumpil JJ, Keough-Ryan T, Kiberd M, Lawen J, Kiberd BA: Treatment of hypercholesterolemia with ezetimibe in the kidney transplant population. Transplant Proc 2005;37:1033-1035.

12 Kasiske BL, Snyder JJ, Gilbertson D, Matas AJ: Diabetes mellitus after kidney transplantation in the United States. Am J Transplant 2003;3:178-185.

13 Report of the expert committee on the diagnosis and classification of diabetes mellitus. Diabetes Care 2003;26(suppl 1):S5-S20.

14 Wilkinson A, Davidson J, Dotta F, Home PD, Keown P, Kiberd B, et al: Guidelines for the treatment and management of new-onset diabetes after transplantation. Clin Transplant 2005;19:291-298.

15 Vanrenterghem Y, Ponticelli C, Morales JM, Abramowicz D, Baboolal K, Eklund B, et al: Prevalence and management of anemia in renal transplant recipients: a European survey. Am J Transplant 2003;3:835-845.

16 Kasiske BL, Vazquez MA, Harmon WE, Brown RS, Danovitch GM, Gaston RS, et al: Recommendations for the outpatient surveillance of renal transplant recipients. American Society of Transplantation. J Am Soc Nephrol 2000;11(suppl 15):S1-S86.
17 Mix TC, Kazmi W, Khan S, Ruthazer R, Rohrer R, Pereira BJ, et al: Anemia: a continuing problem following kidney transplantation. Am J Transplant 2003;3:14261433.

18 Rigatto C: Anemia, renal transplantation, and the anemia paradox. Semin Nephrol 2006;26:307-312.

19 IV. NKF-K/DOQI Clinical Practice Guidelines for Anemia of Chronic Kidney Disease: update 2000. Am J Kidney Dis 2001;37(1 suppl 1):S182-S238.

20 Bia M: Evaluation and management of bone disease and fractures post transplant. Transplant Rev (Orlando) 2008;22:52-61.

21 Nisbeth U, Lindh E, Ljunghall S, Backman $\mathrm{U}$, Fellstrom B: Increased fracture rate in diabetes mellitus and females after renal transplantation. Transplantation 1999;67:12181222 .

22 Julian BA, Laskow DA, Dubovsky J, Dubovsky EV, Curtis JJ, Quarles LD: Rapid loss of vertebral mineral density after renal transplantation. N Engl J Med 1991;325:544550.

-23 Palmer SC, Strippoli GF, McGregor DO: Interventions for preventing bone disease in kidney transplant recipients: a systematic review of randomized controlled trials. Am J Kidney Dis 2005;45:638-649.

24 Coco M, Glicklich D, Faugere MC, Burris L, Bognar I, Durkin P, et al: Prevention of bone loss in renal transplant recipients: a prospective, randomized trial of intravenous pamidronate. J Am Soc Nephrol 2003;14:26692676.

-25 Karthikeyan V, Karpinski J, Nair RC, Knoll G: The burden of chronic kidney disease in renal transplant recipients. Am J Transplant 2004;4:262-269. 
26 Halloran PF, Melk A, Barth C: Rethinking chronic allograft nephropathy: the concept of accelerated senescence. J Am Soc Nephrol 1999;10:167-181.

-27 Artz MA, Hilbrands LB, Borm G, Assmann KJ, Wetzels JF: Blockade of the renin-angiotensin system increases graft survival in patients with chronic allograft nephropathy. Nephrol Dial Transplant 2004; 19:28522857.

-28 Lin J, Valeri AM, Markowitz GS, D’Agati VD, Cohen DJ, Radhakrishnan J: Angiotensin converting enzyme inhibition in chronic allograft nephropathy. Transplantation 2002;73:783-788.

-29 Nankivell BJ, Borrows RJ, Fung CL, O'Connell PJ, Allen RD, Chapman JR: The natural history of chronic allograft nephropathy. N Engl J Med 2003;349:2326-2333.

-30 Mulay AV, Hussain N, Fergusson D, Knoll GA: Calcineurin inhibitor withdrawal from sirolimus-based therapy in kidney transplantation: a systematic review of randomized trials. Am J Transplant 2005;5:17481756.
31 Mulay AV, Cockfield S, Stryker R, Fergusson D, Knoll GA: Conversion from calcineurin inhibitors to sirolimus for chronic renal allograft dysfunction: a systematic review of the evidence. Transplantation 2006;82:11531162.

32 Chadban S: Glomerulonephritis recurrence in the renal graft. J Am Soc Nephrol 2001;12: 394-402.

33 Fishman JA: Infection in solid-organ transplant recipients. N Engl J Med 2007;357: 2601-2614.

34 Humar A, Lebranchu Y, Vincenti F, Blumberg EA, Punch JD, Limaye AP, et al: The efficacy and safety of 200 days valganciclovir cytomegalovirus prophylaxis in high-risk kidney transplant recipients. Am J Transplant 2010;10:1228-1237.

35 Kotton CN, Ryan ET, Fishman JA: Prevention of infection in adult travelers after solid organ transplantation. Am J Transplant 2005;5:8-14.

36 Kasiske BL, Snyder JJ, Gilbertson DT, Wang C: Cancer after kidney transplantation in the United States. Am J Transplant 2004;4:905913.
>37 Morath C, Mueller M, Goldschmidt H, Schwenger V, Opelz G, Zeier M: Malignancy in renal transplantation. J Am Soc Nephrol 2004;1582-1588.

38 Mathew T, Kreis H, Friend P: Two-year incidence of malignancy in sirolimus-treated renal transplant recipients: results from five multicenter studies. Clin Transplant 2004; 18:446-449.

39 McKay DB, Josephson MA, Armenti VT, August P, Coscia LA, Davis CL, et al: Reproduction and transplantation: report on the AST Consensus Conference on Reproductive Issues and Transplantation. Am J Transplant 2005;5:1592-1599.

40 Pirsch JD, Armbrust MJ, Knechtle SJ, D’Alessandro AM, Sollinger HW, Heisey DM, et al: Obesity as a risk factor following renal transplantation. Transplantation 1995; 59:631-633.

41 Sung RS, Althoen M, Howell TA, Ojo AO, Merion RM: Excess risk of renal allograft loss associated with cigarette smoking. Transplantation 2001;71:1752-1757. 